\title{
Effect of Naltrexone on Relaxation Induced by Flank Pressure in Pigs
}

\author{
TEMPLE GRANDIN,$*$ NICHOLAS DODMAN $\dagger$ AND LOUIS SHUSTER $\ddagger$ \\ *Grandin Livestock Handling Systems Inc., 1401 Silver Street, Urbana, IL 61801 \\ Tufts University School of Veterinary Medicine, †Department of Anesthesiology \\ 200 Westboro Road, Grafton, MA 01536 \\ and $\ddagger$ Tufts University School of Medicine, Department of Pharmacology and Biochemistry \\ 136 Harrison Avenue, Boston, MA 02111
}

Received 7 September 1988

\begin{abstract}
GRANDIN, T., N. DODMAN AND L. SHUSTER. Effect of naltrexone on relaxation induced by flank pressure in pigs. PHARMACOL BIOCHEM BEHAV 33(4) 839-842, 1989.- Twenty, 6 to $9 \mathrm{~kg}$ Yorkshire piglets were used in 2 trials. Ten piglets received an IM injection of naltrexone at a dose of 1 to $1.3 \mathrm{mg} / \mathrm{kg}$. Ten control pigs received saline. Blind behavioral testing in a "squeeze chute" was conducted 40 minutes after injection. The "squeeze chute" consists of two padded plywood panels hinged on a base to form a V. Each pig was squeezed for 60 seconds. After release, each pig remained in the padded V for 10 minutes. There was sufficient room for the pigs to walk a few steps. Both naltrexone- and saline-treated pigs eventually crouched down in the chute and relaxed against the padded sides of the $\mathrm{V}$. Naltrexone-pretreated pigs had a longer latency to achieve relaxation $-311.8 \pm 47.8$ seconds vs. $161.8 \pm 30.38$ seconds (SE) $(p<0.02)$. Each stage of relaxation at induction was rated on a $1-4$ scale $(1=$ squealing and jumping, $4=$ relaxed quietly). Naltrexone-treated pigs had significantly lower relaxation ratings than saline-treated pigs $(1.90$ vs. 3.20$)$ $(p<0.01)$. Treatment had no effect on the final degree of relaxation. Naltrexone partially blocked the relaxation response.
\end{abstract}

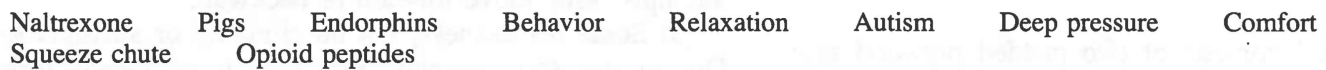

PRESSURE applied to the body will induce relaxation and sleep in both animals and people $(2,5)$. Animal studies indicate that tactile and pressure stimulation will reduce arousal. Rubbing and pinching a cat's paw decreases tonic activity in the dorsal column nuclei and the somatosensory cortex (9). Kumazawa (7) found that pinching a rabbit's skin with one to eight rubber padded clips creates a deactivated EEG pattern. The rabbit will have reduced muscle tone and a drowsy appearance. A twitch placed on a horse's upper lip also has a calming effect and reduces response to pain (8).

Human infants can be calmed by swaddling which applies pressure to large areas of the body (1). Takagi and Kobagasi found that pressure applied to both sides of a person's body reduced metabolic rate, pulse rate, and oxygen consumption (13). Muscle tone was also reduced. Therapists have found that providing hyperactive and autistic children with sources of comfortable deep pressure over large areas of their body improves behavior and reduces hyperactivity (2) (King, personal communication). Grandin (4) designed and built a device which applied pressure to the lateral surfaces of autistic persons in order to reduce nervousness and anxiety.

The pig is an ideal animal to use in tactile comfort studies because pigs seek tactile contact with other individuals. Pigs prefer to lie up against a solid surface (6) or against each other. Observations in slaughter plants indicate that pigs will calm down and stop squealing when they are placed in a V trough restrainer with their legs protruding through the bottom. The animals will be squealing and struggling in the single file chute which leads to the restrainer, but many calm down immediately when they feel the pressure of the $\mathrm{V}$ trough against their sides. Pigs left in the $\mathrm{V}$ trough during lunch breaks will often go to sleep. Pigs will readily relax and go to sleep in a smaller version of the squeeze chute described in (4).

The purpose of this experiment was to determine if an opioid antagonist, naltrexone would block the relaxation response in pigs. Knowledge of biochemical mechanisms which mediate the relaxing effect of pressure would help provide an understanding of the relationship between pressure stimulation and relaxation. Study of pig's reaction to pressure against the sides of its body would also be useful in the design of more humane and less stressful animal restraint methods.

\section{METHOD}

Twenty piglets from two litters of five-week old Yorkshire piglets were used in two trials. Piglet weights varied from 6 to 9 $\mathrm{kg}$. To reduce possible genetic effects each trial contained only one litter. The animals were housed in an indoor pen in a mechanically ventilated building in litter mate groups. They were acclimatized to people by daily petting for a week prior to the experiment. Ten piglets received an intra-muscular injection of naltrexone in the quadriceps femoris at a dosage of 1 to $1.3 \mathrm{mg} / \mathrm{kg}$. Dosage varied slightly because coded prefilled syringes were used in the trials. Ten control piglets received a saline injection. 
TABLE 1

TIME FOR RELAXATION

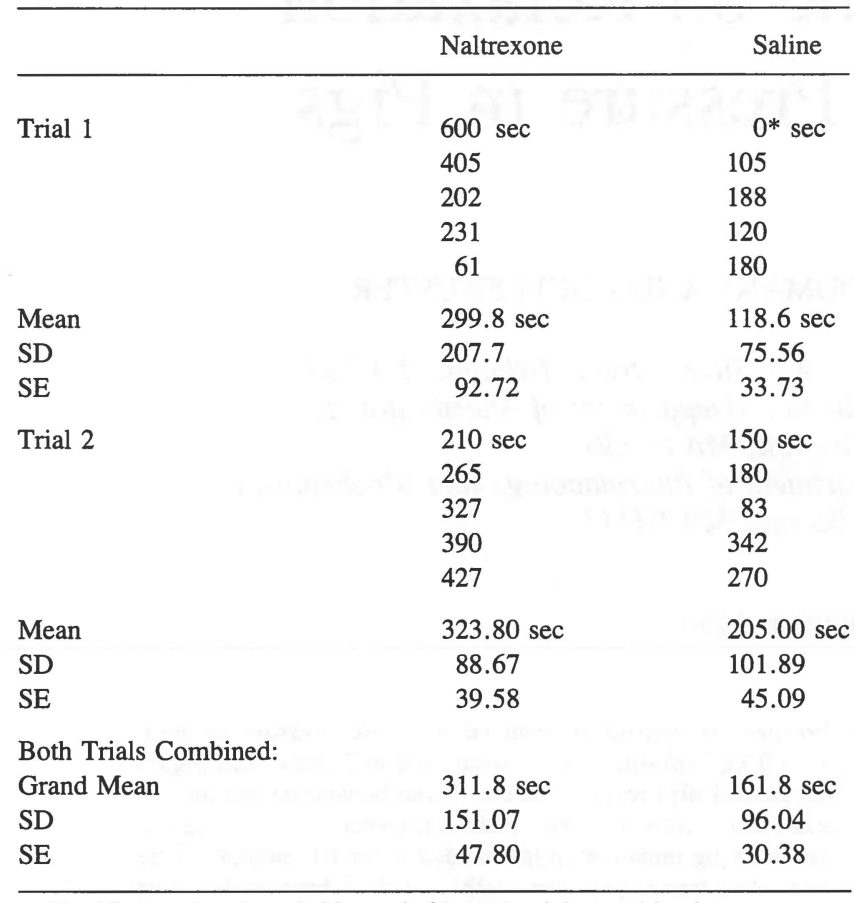

Significance level $p<0.02, t=2.65$, both trials combined.

*Lay down before squeeze could be applied.

Evaluations of animal behavior were done by experimenters blind to treatment. Behavioral testing in the "squeeze chute" started 40 minutes after injection.

The "squeeze chute" consists of two padded plywood side panels which are hinged to a plywood base to form a V. The padding is $2.5 \mathrm{~cm}$ thick foam rubber covered with plastic. The two padded plywood panels are $61 \mathrm{~cm}$ high and $90 \mathrm{~cm}$ long. When the padded panels are in the open position they are spaced $10 \mathrm{~cm}$ apart at the bottom and $51 \mathrm{~cm}$ apart at the top. Measurements are inside of plywood to inside of plywood. Each pig was prevented from leaving the apparatus by a fence panel constructed from narrow bars placed at each end. During the test, the pig in the squeeze chute could see and often touch two penmates through the bars. Isolation is stressful to pigs (10) and the presence of penmates in close proximity helps to reduce stressful effects of isolation.

Each experimental animal was placed in the apparatus and squeezed for 60 seconds. The experimenter pushed the padded side panels against the piglet until it was held firmly but comfortably. A chain fastener was used to hold the panels in the squeezed position. After the squeeze pressure was released each pig was observed until it crouched down and relaxed against the padded $\mathrm{V}$. If an animal showed little or no inclination to relax it was squeezed again. When the squeeze pressure was released there was sufficient room for the piglet to walk back and forth in the $\mathrm{V}$. The test was terminated at 10 minutes if the piglet failed to relax.

The following behavioral data was recorded during the trials.

Time for Induction of Relaxation

This was defined as the time required for the piglet to lower itself down into the bottom of the $\mathrm{V}$ and fully relax. The timer was stopped when the body was fully down and supported by the V.

\section{Relaxation at Induction}

The pigs were graded on a 1 to 4 scale for ease of induction of relaxation.
TABLE 2

RELAXATION AT INDUCTION

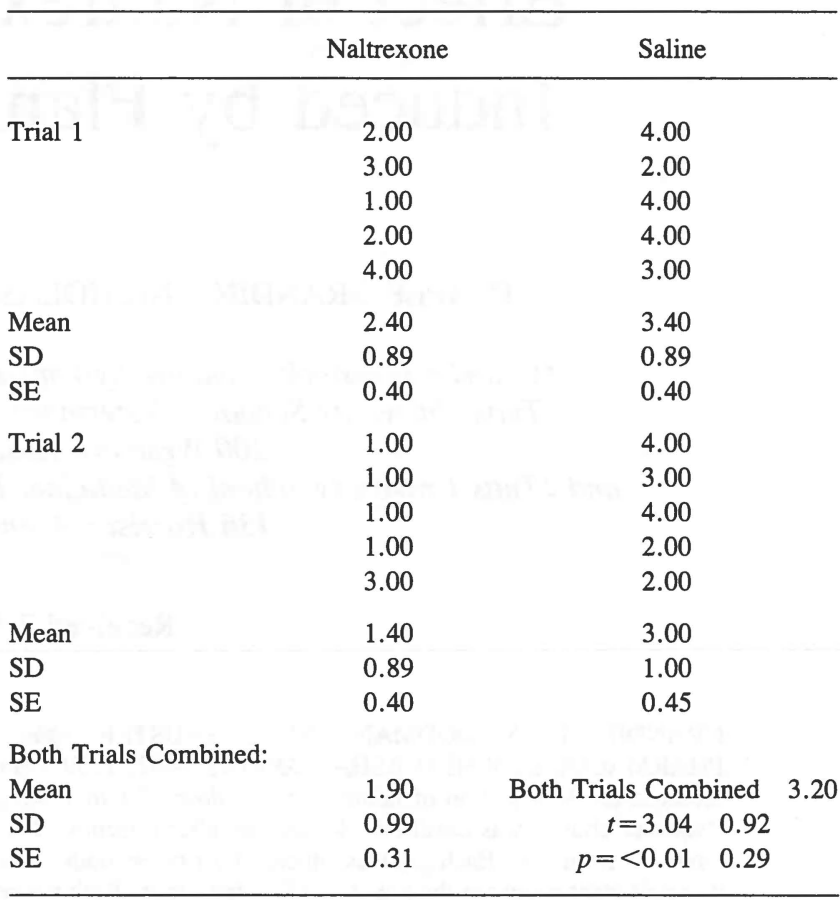

1) Repeated long loud squeals and attempts to escape and climb out.

2) Repeated long loud squeals, but no climbing or escape attempts. May move forward or backward.

3) Some restlessness, but no climbing or attempts to escape. One or two short squeals. Pigs may move slowly forward and backward.

4) Quietly settles down with no squealing, no attempts to escape, and no climbing or forward and backward movement.

\section{Final Relaxation}

The quality of relaxation following induction was also graded on a 1 to 4 scale.

1) Body never fully relaxed before end of the 10-minute test period.

2) Body fully relaxed, but head up and eyes open.

3) Body fully relaxed, head down but eyes are blinking.

4) Body fully relaxed and not supported by the feet. The animal allows its body to be fully supported by the V. The head is down and the eyes are closed

Data was analyzed with a two-tailed $t$-test for a difference between two independent means (3). There were 18 degrees of freedom.

\section{RESULTS}

All pigs in both the naltrexone and saline groups lowered their bodies down into a relaxed body position before the ten-minute cutoff point. Most pigs pressed their snouts against the front bars and lowered the front end of their body first. They then lowered their hind end and tucked up their rear legs up under themselves. The pigs apparently pulled up their legs purposely so their bodies would be fully supported by the padded V trough. The animals then moved their bodies from side to side which wedged them deeper into the $\mathrm{V}$ trough. A pig in this position was not trapped and could easily stand back up if it wished. 
TABLE 3

FINAL RELAXATION

\begin{tabular}{|c|c|c|c|}
\hline & Naltrexone & & Saline \\
\hline \multirow[t]{5}{*}{ Trial 1} & 2.50 & & 4.00 \\
\hline & 3.00 & & 4.00 \\
\hline & 2.00 & & 4.00 \\
\hline & 2.00 & & 2.50 \\
\hline & 3.00 & & 4.00 \\
\hline Mean & 2.50 & & 3.70 \\
\hline SD & 0.50 & & 0.67 \\
\hline SE & 0.22 & & 0.30 \\
\hline \multirow[t]{5}{*}{ Trial 2} & 3.50 & & 2.75 \\
\hline & 2.00 & & 3.50 \\
\hline & 3.50 & & 2.50 \\
\hline & 3.50 & & 3.00 \\
\hline & 4.00 & & 4.00 \\
\hline Mean & 3.30 & & 3.15 \\
\hline SD & 0.75 & & 0.60 \\
\hline SE & 0.33 & & 0.26 \\
\hline \multicolumn{4}{|c|}{ Both Trials Combined: } \\
\hline Mean & 2.90 & Both Trials Combined & 3.43 \\
\hline $\mathrm{SD}$ & 0.73 & $t=1.15$ & 0.68 \\
\hline SE & 0.23 & $p=\mathrm{N} . \mathrm{S}$. & 0.21 \\
\hline
\end{tabular}

Animals in the naltrexone group had a longer latency to attain the relaxed position, $311.8 \pm 47.80$ seconds (SE) versus $161.8 \pm 30.38$ seconds (SE) for naltrexone- and saline-treated groups, respectively (Table 1) $(p<0.02)$. Pigs in the naltrexone group also had a lower mean relaxation rating at induction of 1.90 versus 3.20 for the saline group (Table 2) $(p<0.01)$, indicating that they were more likely to squeal and make attempts to escape. Only one of the naltrexone-treated pigs achieved a relaxation rating of 4 . Five out of ten of the saline pigs received a relaxation rating of 4 at induction. Final relaxation ratings were not significantly different (Table 3). There was also no significant effect on heart rate. Heart rates were $143.2 \pm 4.1 \mathrm{SE}(\mathrm{SD}=12.30)$ versus $141.7 \pm 4.79 \mathrm{SE}$ $(\mathrm{SD}=15.14)$ for naltrexone and saline respectively. When the piglets were lifted out of the apparatus heart rates greatly increased.

\section{DISCUSSION}

The observation of increased squealing in the naltrexonetreated group is similar to the findings of Panksepp (11) of increased distress vocalizations in naloxone-treated puppies, guinea pigs, and chicks. Panksepp (11) also reported that naloxone increased the latency to sleep when young chicks were comfortably held in cupped human hands. The results from our pigs were similar. Naltrexone increased the time required to induce relaxation but it did not completely block the relaxation response. To completely block the sleep and relaxation response in chicks, they must be given antagonists to endorphins, acetylcholine and serotonin (12).

Naltrexone had no obvious effect on the behavior of the pigs when they were all in their pens together. Both naltrexone and saline pigs were housed together and a casual observer could not differentiate between them.

In the first trial the pigs had a tendency to have higher relaxation ratings at induction indicating quicker and calmer induction. The pigs in this trial had three previous experiences in the squeeze chute, whereas the pigs in the second trial had only one brief prior experience. In general, the latter group had lower relaxation ratings at induction. There was a tendency for induction of relaxation to become easier with repeated experiences. Squealing and attempts to escape decline after repeated experiences. The pigs did not appear to fear the squeeze chute. When the end panels were removed they readily approached it and some animals walked through it.

It is unlikely that the results are due to stress-induced analgesia because the pigs were free to stand and walk back and forth after the squeeze was released. Each animal voluntarily lowered its body and relaxed. Another indicator that stress-induced analgesia was not the cause of the relaxation effect is that the pigs readily approached the squeeze chute after they had been in it.

There was also individual variation in pig response to repeated experiences in the squeeze chute. The pigs in group one were induced to relax six times. The heaviest piglet in the group had a final relaxation score of 2.00 or less on four out of six trials. The heaviest animals are usually socially dominant and this may explain why they are less likely to submit. One calm medium weight pig always exceeded a score of 3.50 .

The pigs in this experiment were all naive to any drug. In a preliminary test, the same animals were switched back and forth three times every 24 hours between naltrexone and saline. This resulted in no treatment differences on all three measures. Some of the conflicting results reported in the literature on opioid peptides antagonists may possibly be explained by differences in experimental design.

\section{CONCLUSIONS}

Pressure on the sides of a pig's body in a comfortable padded apparatus will induce pigs to relax. Naltrexone injections increased the time required to induce relaxation but it did not completely block the response. Naltrexone also increased resistance to induction of relaxation.

\section{REFERENCES}

1. Anderson, J. Sensory intervention with the pre-term infant in the neonatal intensive care unit. Am. J. Occup. Ther. 40:19-26; 1986.

2. Ayres, J. A. Sensory integration and the child. Los Angeles: Western Psychological Services; 1979:141.

3. Burning, J. L.; Kintz, B. L. Computational handbook of statistics. Glenview, IL: Scott, Foresman and Company; 1968:9-12.

4. Grandin, T. Emergence labelled autistic. Novato, CA: Arena Press; 1986:178-179.

5. Grandin, T. My experiences as an autistic child and review of selected literature. J. Orthomol. Psychiatry 13:144-174; 1984.

6. Hartsock, T. G. Maladaptive behaviors of piglets weaned at 12 hours postpartum. J. Anim. Sci. 49(Suppl. 1):147; 1979.

7. Kumazawa, T. Deactivation of the rabbits brain by pressure application on the skin. Electroencephalogr. Clin. Neurophysiol. 15:660-
$671 ; 1963$.

8. Lagerweij, E. L.; Nelis, P. C.; Wiegant, V. M.; VanRee, J. M. The twitch in horses: a variant of acupuncture. Science 225:1172-1174; 1984.

9. Melzack, R.; Konrad, K. W.; Dubrobsky, B. Prolonged changes in the central nervous system activity produced by somatic and reticular stimulation. Exp. Neurol. 25:416-428; 1969.

10. Mertsching, H. J.; Kelly, K. W. Restraint reduces size of thymus gland and PHA swelling in pigs. J. Anim. Sci. 57(Suppl. 1):175-176; 1983.

11. Panksepp, J.; Herman, B. H.; Vilberg, T.; Bishop, P.; DeEskinazi, F. G. Endogenous opioids and social behavior. Neurosci. Biobehav. Rev. 4:473-487; 1978

12. Panskepp, J.; Bean, N. J.; Bishop, P.; Vilberg, T.; Sahley, T. L. 
Opioid blockade and social comfort in chicks. Pharmacol, Biochem. Behav. 13:673-683; 1980.
13. Takagi, K.; Kobagasi, S. Skin pressure reflex. Acta Med. Biol. 4:81-91; 1956. 